\title{
5-Aminolevulinic acid could enhance the salinity tolerance by alleviating oxidative damages in Salvia miltiorrhiza
}

\author{
Xin LI $^{1}{ }^{(D)}$, Juanjuan $\mathrm{LI}^{1}$, Faisal ISLAM ${ }^{2}$, Ullah NAJEEB ${ }^{3}$, Jianmin $\mathrm{PAN}^{1}$, Zhuoni HOU ${ }^{1}$, Jianyao SHOU ${ }^{4 *}$, \\ Yebo QIN ${ }^{5 *}$, Ling XU ${ }^{1 *}$ (D)
}

\begin{abstract}
S. miltiorrhiza is a Chinese medicinal plant that is widely cultivated. The root growth in S. miltiorrhiza are inhibited by soil salinity. Here we investigated the capability of a plant growth regulator, 5-ALA to promote the growth of $S$. miltiorrhiza under different salt stresses. Five-month old S. miltiorrhiza roots were uniformly irrigated with different levels of salt solution i.e. 0 , $100,200 \mathrm{mM} \mathrm{NaCl}$. After 3 days of treatment, salt-treated S. miltiorrhiza plants were sprayed with different concentrations of ALA $\left(0,10 \mathrm{mg} \mathrm{L}^{-1}, 20 \mathrm{mg} \mathrm{L}^{-1}\right)$ on the leaves and cultured for another 7 days. Results revealed that ALA treated plants produced significantly higher biomass by sustaining leaf chlorophyll content under salt stressed. $10 \mathrm{mg} \mathrm{L}^{-1} \mathrm{ALA}$ significantly up-regulated antioxidant enzymes activities under studied salinity treatments. Positive effects of ALA on antioxidant defense systems were also supported by a significant increase in the expression of SOD isoenzymes genes (CSD1, FSD1 and MSD2), defense response genes (DXS1, C4H, GGPPS) and stress-related gene (MYB36, MYB39) of ALA treated plants. This study suggested that ALA can protect $S$. miltiorrhiza from salinity induced oxidative stress and injury by promoting antioxidant defense system, boosting secondary metabolic pathways and protecting photosynthetic pigments.
\end{abstract}

Keywords: 5-aminolevulinic acid (ALA); gene regulation; oxidative stress; salinity stress; Salvia miltiorrhiza.

Practical Application: Salinity tolerance was enhanced by spraying 5-Aminolevulinic acid on leaves in Salvia miltiorrhiza.

\section{Introduction}

Salinity, drought, cold, and extreme temperature are the major abiotic stresses which restrain the growth and development of plants (Guo et al., 2018). Among these, soil salinity has become a major yield limiting factor for cultivated crops in many parts of the world (Khan et al., 2019). In the north-western inland of China, for instance, soil salinization is universal problem because of limited rainfall, high evapotranspiration, and possible poor soil water management. Besides, saline soils occurred on the eastern coastline of China (Gengmao et al., 2014). Increased accumulation of salts in the soil has negatively impacted agricultural production (Abogadallah, 2010). Salinity could affect the functions of normal plants through osmotic stress, ion imbalance and oxidative damage (Tufail et al., 2018). Salinity stressed plants might capture these enhanced ROS by modifying the activities of antioxidant enzymes, for instance POD, APX and SOD (Gengmao et al., 2014). Some plants i.e. sunflowers and some medicinal plants have negative effects under saline soils (Liu \& Shi, 2010; Guo et al., 2018). Thus, investigation of salt tolerance mechanisms of these plants are very important for the further salinity tolerance breeding.

5-aminolevulinic acid (ALA) is an important precursor for heme and chlorophyll (Ali et al., 2014; Li et al., 2019a). Thus, application of ALA could enhance the plant tolerance against various stresses. It has been reported that ALA could increase the net photosynthetic rate, chlorophyll content, antioxidant activities and inhibit the uptake and translocation of $\mathrm{Na}^{+}$in cotton seedlings under salinity stress (Watanabe et al., 2000). ALA could improve photosynthetic rate and chlorophyll content of melon seedlings under low light and chilling conditions (Wang et al., 2004). Application of ALA can significantly recovery the rapeseed seedlings from heavy metals induced toxicity by increasing antioxidant enzyme activities, suppressing ROS and MDA contents and recovering the ultra-structural damages (Ali et al., 2013 a, b, c; Ali et al., 2014; Ali et al., 2015).

S. miltiorrhiza, as a functional food, is one of the most extensively studied medicinal plants, which is used as human medicine and health-promotion food. (Shi et al., 2018). Tanshinone in S. miltiorrhiza has definite curative effect on cardiovascular diseases and neurological diseases(Hao et al., 2015; Xu et al., 2021). Recently, tanshinone has been found to have an inhibitory effect on human bladder cancer cells (Huang et al., 2020). In addition, Gengmao et al. (2014) found that the adaptive response to salt stress in S. miltiorrhiza was linked with its highly induced antioxidant enzyme defense systems. Guo et al. (2018) reported Sm-miR408 in S. miltiorrhiza is involved in adaptative responses of salinity stress by modulating the activities of

${ }^{1}$ Zhejiang Province Key Laboratory of Plant Secondary Metabolism and Regulation, College of Life Sciences and Medicine, Zhejiang Sci-Tech University, Hangzhou, China

${ }^{2}$ Institute of Crop Science, Ministry of Agriculture and Rural Affairs Laboratory of Spectroscopy Sensing, Zhejiang University, Hangzhou, China

${ }^{3}$ Queensland Alliance for Agriculture and Food Innovation, Centre for Plant Science, The University of Queensland, Toowoomba, Australia

${ }^{4}$ Zhuji Municipal Agro-Tech Extension Center, Zhuji, China

${ }^{5}$ Zhejiang Agricultural Technology Extension Center, Hangzhou, China

*Corresponding authors: zjsjy.639@163.com, qyb.leaf@163.com,1xu@zstu.edu.cn 
antioxidant enzymes i.e. SOD, POD and CAT. S. miltiorrhiza might maintain its growth under salinity stress by up-regulating its antioxidant system. Therefore, exploiting the induced tolerance in S. miltiorrhiza might become a useful tool for broadening the cultivation area of S. miltiorrhiza and minimizing the negative effects of salinity stress.

To date, less information is available on the use of plant growth regulators for increasing salinity tolerance in S. miltiorrhiza. Therefore, this study aims are (i) to reveal physio-biochemical changes induced by salinity stress in S. miltiorrhiza, (ii) to investigate the recovery mechanisms of exogenous application of ALA in alleviating salt induced injuries in S. miltiorrhiza. The study will provide insights into the positive effects of ALA on enhancing the salinity tolerance, and provide candidate genes for salinity tolerance breeding in S. miltiorrhiza.

\section{Materials and methods}

\subsection{Plant growth}

Healthy seeds of S. miltiorrhiza, cv. Tiandan 1, were obtained from Shaanxi Tasly Plant Pharmaceutical Co., Ltd, China and cultured in greenhouse of Zhejiang Sci-Tech University, Hangzhou, China.

The uniform S. miltiorrhiza seedlings were selected for the following experiments, after 5 months of culture. Three concentrations of salt $(0,100$ or $200 \mathrm{mM} \mathrm{NaCl})$ were used according to our preliminary experiment. To avoid stress shock, salt stress was imposed in stepwise manner $(50 \mathrm{mM} \mathrm{NaCl}$ increment with each irrigation per day) to the plants in soil (Islam et al., 2018). After 3 days of salt stress treatment, the plants were sprayed with ALA (10 or $20 \mathrm{mg} \mathrm{L}^{-1}$ ) and then cultured for another 7 days. The treatment combinations contained: control, $100 \mathrm{mM} \mathrm{NaCl}$, $200 \mathrm{mM} \mathrm{NaCl}, 10 \mathrm{mg} \mathrm{L}^{-1} \mathrm{ALA}, 20 \mathrm{mg} \mathrm{L}^{-1} \mathrm{ALA}, 10 \mathrm{mg} \mathrm{L}^{-1} \mathrm{ALA}+$ $100 \mathrm{mM} \mathrm{NaCl}, 10 \mathrm{mg} \mathrm{L}^{-1} \mathrm{ALA}+200 \mathrm{mM} \mathrm{NaCl}, 20 \mathrm{mg} \mathrm{L}^{-1} \mathrm{ALA}$ + $100 \mathrm{mM} \mathrm{NaCl}, 20 \mathrm{mg} \mathrm{L}^{-1} \mathrm{ALA}+200 \mathrm{mM} \mathrm{NaCl}$. After seven days of ALA recovery treatments, root and leaf tissues were collected for physiological and biochemical analyses with three biological replicates.

\subsection{Leaf chlorophyll and carotenoid contents}

Fresh leaf sample (100 mg) was used for chlorophylla (Chl a), chlorophyllb (Chl b) and carotenoid contents analyses. The leaf tissues were ground in $5 \mathrm{~mL}$ of acetone and ethanol mixture under dark conditions. The supernatant was used for measuring absorbance at $663 \mathrm{~nm}, 645 \mathrm{~nm}$ and $470 \mathrm{~nm}$ (Lichtenthaler, 1987).

\subsection{Reactive oxygen species (ROS) and malondialdehyde (MDA)}

Reactive oxygen species i.e. hydrogen peroxide $\left(\mathrm{H}_{2} \mathrm{O}_{2}\right)$, hydroxyl radical $(-\mathrm{OH})$ and superoxide radical $\left(\mathrm{O}_{2}^{-}\right)$in different S. miltiorrhiza tissues were measured using a Microplate Reader (Synergy HTX). Extracellular ${ }^{-} \mathrm{OH}$ contents were measured using an extinction coefficient of $0.28 \mathrm{~mm}^{-1} \mathrm{~cm}^{-1}$ according to the method of Halliwell et al. (1987). Absorbance of $\mathrm{O}_{2}^{-}$was taken at $530 \mathrm{~nm}$ (Jiang \& Zhang, 2001), and $\mathrm{O}_{2}^{-}$production rate was determined using a standard curve method (Zhou \& Leul, 1999). MDA content were determined at $532 \mathrm{~nm}$ and $600 \mathrm{~nm}$ by thiobarbituric acid chromogenic method according to Zhou \& Leul (1999).

\subsection{Antioxidant enzyme activities}

A Microplate Reader (Synergy HTX) was used for measuring antioxidant enzymes in $S$ miltiorrhiza tissues. Photoredox method of nitrogen blue tetrazole was used for measuring SOD activity (Zhang et al., 2008). For POD activity measurement, guaiacol oxidation method was used from the changes in the absorbance of reaction mixture (extinction coefficient $26.6 \mathrm{~mm}^{-1} \mathrm{~cm}^{-1}$ ) within 1 minute at $470 \mathrm{~nm}$ (Zhou \& Leul, 1999). CAT activity was determined from the degradation of $\mathrm{H}_{2} \mathrm{O}_{2}$ in the reaction mixture within 1 minute at $240 \mathrm{~nm}$ (Aebi, 1984). APX activity was determined from the changes in absorbance of reaction mixture at $290 \mathrm{~nm}$, according to the protocol of Nakano \& Asada (1981).

\subsection{Gene expression analyses}

RNA extraction, cDNA reverse transcription and qRT-PCR methods were performed according to Xu et al. (2019). In addition, the primers were listed in Table 1 including the SOD isoenzymes genes CSD1, FSD1, MSD2 (Han et al., 2020), the genes related to secondary metabolites, such as DXS1, C4H, GGPPS, HMGR, PAL in the metabolic pathway of active ingredient of $S$. miltiorrhiza (Xing et al., 2018). The genes' expressions were calculated using the method of $2^{-\Delta \Delta \mathrm{CT}}$ (Livak \& Schmittgen, 2001).

\subsection{Statistical analysis}

For morphological and physiological parameters, three biological replicates were conducted for each treatment combination. The gene expression data were recorded as the average of three biological replicates and three technical replicates. Data were analyzed using SPSS 22.0 (SPSS, Chicago, IL, USA), fisher least significant difference (LSD) test, two-way analysis of variance (ANOVA), and Duncan's multiple range test were used to determine the significant differences $(P \leq 0.05)$ between individuals. The results of morphological and physiological parameters were presented as mean \pm standard error (SE).

\section{Results}

\subsection{Plant growth}

In the absence of ALA treatment, S. miltiorrhiza plants experienced a significant reduction in plant height, root length and biomass production under salinity treatments (Table 2). $10 \mathrm{mg} \mathrm{L}^{-1} \mathrm{ALA}$ significantly improved the growth and increased the fresh weights of leaves and roots of S. miltiorrhiza under different salinity stresses. For instance, ALA treated plants produced $34.21 \%$ and $30.08 \%$ higher leaf and root fresh weight, respectively, as compared to $100 \mathrm{mM}$ salinity treatment alone. Whereas, higher doses of ALA (20 $\left.\mathrm{mg} \mathrm{L}^{-1}\right)$ had negative effects on plant growth, especially on dry weights of roots under high salt stressed plants $(200 \mathrm{mM} \mathrm{NaCl})$. For instance, dry weight of roots under the treatment of $20 \mathrm{mg} \mathrm{L}^{-1} \mathrm{ALA}+200 \mathrm{mM} \mathrm{NaCl}$ 
declined $31.91 \%$, as compared to the $200 \mathrm{mM} \mathrm{NaCl}$ treatment alone. This suggests that selection of an optimum level of ALA i.e. $10 \mathrm{mg} \mathrm{L}^{-1}$ is crucial for protecting $S$. miltiorrhiza plants from salinity stress injury.

\subsection{Leaf pigments}

Increasing $\mathrm{NaCl}$ concentrations in the growth media significantly reduced $\mathrm{Chl} \mathrm{a}, \mathrm{Chl} \mathrm{b}$ and carotenoid contents of S. miltiorrhiza (Table 3). $10 \mathrm{mg} \mathrm{L}^{-1}$ ALA significantly increased the $\mathrm{Chl}$ a, Chl b, total Chlorophyll and carotenoid contents of $S$. miltiorrhiza as compared with the control, on the contrary, $20 \mathrm{mg}$
$\mathrm{L}^{-1} \mathrm{ALA}$ could significantly reduce chlorophyll and carotenoid contents. In addition, low dosage of ALA $\left(10 \mathrm{mg} \mathrm{L}^{-1}\right)$ had obvious recovery effects on the chlorophyll and carotenoid contents of S. miltiorrhiza under different salinity stresses. For instance, application of $10 \mathrm{mg} \mathrm{L}^{-1} \mathrm{ALA}$ increased leaf $\mathrm{Chl} \mathrm{a,} \mathrm{Chl} \mathrm{b}$ and carotenoid contents of S. miltiorrhiza by $127.75 \%, 31.90 \%$ and $64.10 \%$ respectively, as compared with the $100 \mathrm{mM}$ salinity stress alone. However, under the treatment of high salinity treatment of $200 \mathrm{mM} \mathrm{NaCl}$, high dosage of ALA (20 mg L-1) could significantly reduce the Chla, Chlb, total and carotenoid contents of $S$. miltiorrhiza as compared to low dosage of ALA (10 $\left.\mathrm{mg} \mathrm{L}^{-1}\right)$.

Table 1. List of qRT-PCR primer used in present study.

\begin{tabular}{cccc}
\hline Gene & Sense Primer (5’ to 3') & Reverse Prime (5' to 3') & GenBank/Gene ID \\
\hline Actin & GGTGCCCTGAGGTCCTGTT & AGGAACCACCGATCCAGACA & HM231319 \\
CSD1 & CGTCAGCTTCACTCAGGAGG & GCTCTTTGCCAGCAGGATTG & SMil_00004513 \\
FSD1 & CTCATTTGGGAGGGGCACAG & CGAGCGTTCTCTGGCTCATA & SMil_00006812 \\
MSD2 & TTGCTCCTGTTCGTGTTGGT & CAAGCCACACCCATCCTGAA & SMil_00025343 \\
DXS1 & CGACCAGGTAGTGCACGACG & TCATCTGAAGGAGCCATCACCAC & EU670744 \\
C4H & CCAGGAGTCCAAATAACAGAGCC & GAGCCACCAAGCGTTCACCAA & EF377337 \\
GGPPS & GGGGCTATTTTGGGAGGTGGAA & CAGCAGCTTGGGATACGTGGTC & FJ178784 \\
HMGR & GCAACATCGTCTCCGCCGTCTACA & GATGGTGGCCAGCAGCCTGGAGTT & FJ747636 \\
$P A L$ & GGCGGCGATTGAGAGCAGGA & ATCAGCAGATAGGAAGAGGAGCACC & GQ249111 \\
$M Y B 36$ & TCTCCGATGCTGAAGAGGAC & CTTCATTGCTGCGGTTGAGA & KF059390 \\
$M Y B 39$ & ATGCCCAACCACCAACAATC & ATTTCTACGCCGGGATTTGC & KF059393 \\
\hline
\end{tabular}

Table 2. Effects of 5-aminolevulinic acid on plant growth and biomass of S. miltiorrhiza under different salinity stresses.

\begin{tabular}{|c|c|c|c|c|c|c|c|}
\hline \multirow{2}{*}{$\begin{array}{c}\text { ALA level (mg } \\
\left.\mathrm{L}^{-1}\right)\end{array}$} & \multirow{2}{*}{$\begin{array}{l}\mathrm{NaCl} \text { level } \\
(\mathrm{mM})\end{array}$} & \multirow{2}{*}{ Plant height $(\mathrm{cm})$} & \multirow{2}{*}{ Root length $(\mathrm{cm})$} & \multicolumn{2}{|c|}{ Leaf weight $\left(\mathrm{g} \mathrm{plant}^{-1}\right)$} & \multicolumn{2}{|c|}{ Root weight ( g plant $^{-1}$ ) } \\
\hline & & & & Fresh & Dry & Fresh & Dry \\
\hline \multirow{3}{*}{0} & 0 & $12.367 \pm 0.379 \mathrm{a}$ & $18.883 \pm 0.535 b$ & $1.860 \pm 0.120 \mathrm{~b}$ & $0.243 \pm 0.031 b$ & $1.940 \pm 0.120 \mathrm{~b}$ & $0.587 \pm 067 b$ \\
\hline & 100 & $11.100 \pm 0.529 b c$ & $16.817 \pm 1.042 \mathrm{c}$ & $1.400 \pm 0.140 c$ & $0.213 \pm 0.001 c$ & $1.443 \pm 0.045 \mathrm{~d}$ & $0.493 \pm 0.060 \mathrm{de}$ \\
\hline & 200 & $10.467 \pm 0.450 \mathrm{c}$ & $16.417 \pm 1.010 \mathrm{c}$ & $1.245 \pm 0.025 \mathrm{~cd}$ & $0.187 \pm 0.012 \mathrm{de}$ & $1.307 \pm 0.141 \mathrm{de}$ & $0.445 \pm 0.015 \mathrm{~d}$ \\
\hline \multirow{3}{*}{10} & 0 & $11.767 \pm 0.493 \mathrm{ab}$ & $21.313 \pm 0.563 a$ & $2.080 \pm 0.070 \mathrm{a}$ & $0.288 \pm 0.013 a$ & $2.120 \pm 0.010 \mathrm{a}$ & $0.668 \pm 0.048 \mathrm{a}$ \\
\hline & 100 & $11.433 \pm 0.208 b$ & $19.900 \pm 1.153 \mathrm{ab}$ & $1.879 \pm 0.021 b$ & $0.250 \pm 0.010 \mathrm{~b}$ & $1.877 \pm 0.075 b c$ & $0.575 \pm 0.022 b c$ \\
\hline & 200 & $11.850 \pm 0.550 \mathrm{ab}$ & $19.250 \pm 0.318 \mathrm{a}$ & $1.750 \pm 0.110 \mathrm{~b}$ & $0.206 \pm 0.006 \mathrm{~cd}$ & $1.780 \pm 0.110 \mathrm{e}$ & $0.613 \pm 0.032 \mathrm{ab}$ \\
\hline \multirow{3}{*}{20} & 0 & $11.000 \pm 0.435 b c$ & $19.907 \pm 0.969 \mathrm{ab}$ & $1.410 \pm 0.030 \mathrm{c}$ & $0.207 \pm 0.058 \mathrm{~cd}$ & $1.891 \pm 0.092 b c$ & $0.510 \pm 0.045 \mathrm{~cd}$ \\
\hline & 100 & $11.300 \pm 0.265 b c$ & $18.767 \pm 1.150 \mathrm{~b}$ & $1.203 \pm 0.176 \mathrm{~d}$ & $0.193 \pm 0.006 \mathrm{~cd}$ & $1.297 \pm 0.0150 \mathrm{ce}$ & $0.405 \pm 0.005 \mathrm{e}$ \\
\hline & 200 & $11.133 \pm 0.650 \mathrm{bc}$ & $18.750 \pm 0.450 b$ & $1.277 \pm 0.107 \mathrm{~cd}$ & $0.167 \pm 0.015 \mathrm{e}$ & $1.207 \pm 0.012 \mathrm{e}$ & $0.303 \pm 0.006 f$ \\
\hline
\end{tabular}

Each value is the mean of three replicates. Means followed by same small letters in the same column are not significantly different at $P \leq 0.05$.

Table 3. Effects of 5-aminolevulinic acid on leaf chlorophyll and carotenoid contents of S. miltiorrhiza under different salinity stresses.

\begin{tabular}{|c|c|c|c|c|c|}
\hline \multirow{2}{*}{ ALA level $\left(\mathrm{mg} \mathrm{L}^{-1}\right)$} & \multirow{2}{*}{$\mathrm{NaCl}$ level (mM) } & \multicolumn{3}{|c|}{ Chlorophyll (mg g-1 FW) } & \multirow{2}{*}{$\begin{array}{l}\text { Carotenoids } \\
\left(\mathrm{mg} \mathrm{g}^{-1} \mathrm{FW}\right) \\
\end{array}$} \\
\hline & & Chl a & $\mathrm{Chl} \mathrm{b}$ & Total & \\
\hline \multirow{3}{*}{0} & 0 & $0.746 \pm 0.038 c$ & $0.220 \pm 0.010 \mathrm{~b}$ & $0.959 \pm 0.048 c$ & $0.188 \pm 0.004 c$ \\
\hline & 100 & $0.209 \pm 0.008 f$ & $0.116 \pm 0.003 \mathrm{e}$ & $0.324 \pm 0.010 \mathrm{~g}$ & $0.078 \pm 0.004 \mathrm{~g}$ \\
\hline & 200 & $0.175 \pm 0.014 \mathrm{~g}$ & $0.066 \pm 0.002 f$ & $0.241 \pm 0.016 \mathrm{~h}$ & $0.070 \pm 0.004 h$ \\
\hline \multirow{3}{*}{10} & 0 & $1.246 \pm 0.013 a$ & $0.353 \pm 0.004 a$ & $1.600 \pm 0.017 \mathrm{a}$ & $0.302 \pm 0.003 a$ \\
\hline & 100 & $0.476 \pm 0.010 \mathrm{e}$ & $0.153 \pm 0.017 \mathrm{~d}$ & $0.612 \pm 0.023 f$ & $0.128 \pm 0.004 f$ \\
\hline & 200 & $0.797 \pm 0.010 \mathrm{~b}$ & $0.218 \pm 0.009 b$ & $1.020 \pm 0.010 \mathrm{~b}$ & $0.205 \pm 0.004 b$ \\
\hline \multirow{3}{*}{20} & 0 & $0.449 \pm 0.016 \mathrm{e}$ & $0.156 \pm 0.006 \mathrm{~d}$ & $0.595 \pm 0.016 f$ & $0.137 \pm 0.008 \mathrm{e}$ \\
\hline & 100 & $0.480 \pm 0.024 \mathrm{e}$ & $0.178 \pm 0.004 c$ & $0.658 \pm 0.027 \mathrm{e}$ & $0.157 \pm 0.003 d$ \\
\hline & 200 & $0.607 \pm 0.014 \mathrm{~d}$ & $0.125 \pm 0.003 \mathrm{e}$ & $0.731 \pm 0.017 \mathrm{~d}$ & $0.160 \pm 0.003 d$ \\
\hline
\end{tabular}

Each value is the mean of three replicates. Means followed by same small letters in the same column are not significantly different at $P \leq 0.05$. 


\subsection{Lipid peroxidation and reactive oxygen species}

Increasing salinity levels in the growth media significantly accelerated ROS accumulation and subsequent lipid peroxidation (MDA) in leaf and root tissues of S. miltiorrhiza (Table 4). In contrast, ALA $\left(10 \mathrm{mg} \mathrm{L}^{-1}\right)$ significantly reduced $\mathrm{H}_{2} \mathrm{O}_{2}$ in leaf and root tissue of low salt-stressed plants by $35.44 \%$ and $12.21 \%$, and $\mathrm{OH}$ contents by $28.04 \%$ and $22.26 \%$, respectively, as compared with $100 \mathrm{mM}$ salinity treatment alone. Similarly, lower concentration of ALA significantly reduced MDA and ROS in $S$. miltiorrhiza, except for the $\mathrm{OH}$ content in leaves under $200 \mathrm{mM}$ salinity treatment. However, under low $100 \mathrm{mM}$ salinity stress, higher ALA concentration i.e. $20 \mathrm{mg} \mathrm{L}^{-1}$ significantly increased
MDA and - $\mathrm{OH}$ levels in both leaves and roots of S. miltiorrhiza as compared with those applied with low dosage of ALA $(10 \mathrm{mg}$ $\left.\mathrm{L}^{-1}\right)$. We concluded that low concentration of ALA $\left(10 \mathrm{mg} \mathrm{L}^{-1}\right)$ could effectively reduce ROS and MDA contents of salinitytreated S. miltiorrhiza, as compared to higher concentrations of ALA $\left(20 \mathrm{mg} \mathrm{L}^{-1}\right)$.

\subsection{ROS scavenging enzymes}

Changes in the activities of different antioxidant enzymes of S. miltiorrhiza in response to salinity and ALA treatment were shown in Figure 1. In the leaves and roots of salt-treated S. miltiorrhiza, CAT activity significantly decreased with the

Table 4. Effects of 5-aminolevulinic acid on contents of malondialdehyde (MDA) hydrogen peroxide $\left(\mathrm{H}_{2} \mathrm{O}_{2}\right)$, hydroxyl ion (-OH) and superoxide radical $\left(\mathrm{O}_{2}^{-}\right)$in S. miltiorrhiza under different salinity stresses.

\begin{tabular}{|c|c|c|c|c|c|c|c|c|c|}
\hline \multirow{2}{*}{$\begin{array}{l}\text { ALA conc. } \\
\left(\mathrm{mg} \mathrm{L}^{-1}\right)\end{array}$} & \multirow{2}{*}{$\begin{array}{l}\mathrm{NaCl} \text { conc. } \\
(\mathrm{mM})\end{array}$} & \multicolumn{2}{|c|}{ MDA (nmol g-1 FW) } & \multicolumn{2}{|c|}{$\mathrm{H}_{2} \mathrm{O}_{2}\left(\mu \mathrm{mol} \mathrm{g}{ }^{-1} \mathrm{FW}\right)$} & \multicolumn{2}{|c|}{$\mathrm{OH}\left(\mu \mathrm{mol} \mathrm{g}{ }^{-1} \mathrm{FW}\right)$} & \multicolumn{2}{|c|}{$\mathrm{O}_{2}^{-}\left(\mathrm{nmolmin}^{-1} \mathrm{~g}^{-1} \mathrm{FW}\right)$} \\
\hline & & Leaf & Root & Leaf & Root & Leaf & Root & Leaf & Root \\
\hline \multirow{3}{*}{0} & 0 & $11.470 \pm 0.397 \mathrm{c}$ & $11.237 \pm 0.400 \mathrm{~d}$ & $41.790 \pm 4.256 \mathrm{~d}$ & $54.290 \pm 3.337 \mathrm{de}$ & $14.128 \pm 0.684 \mathrm{~b}$ & $8.840 \pm 0.242 \mathrm{~d}$ & $14.585 \pm 0.246 c$ & $3.539 \pm 0.196 \mathrm{~d}$ \\
\hline & 100 & $12.215 \pm 0.172 b$ & $12.621 \pm 0.394 \mathrm{bc}$ & $63.013 \pm 2.020 \mathrm{~b}$ & $64.223 \pm 2.233 c$ & $16.198 \pm 0.303 a$ & $11.444 \pm 0.273 c$ & $18.114 \pm 0.057 \mathrm{a}$ & $6.356 \pm 0.236 c$ \\
\hline & 200 & $13.259 \pm 0.442 \mathrm{a}$ & $14.005 \pm 0.387 \mathrm{a}$ & $70.484 \pm 0.512 a$ & $94.027 \pm 0.231 \mathrm{a}$ & $17.066 \pm 0.485 a$ & $13.141 \pm 0.341 \mathrm{a}$ & $15.696 \pm 0.353 b$ & $8.663 \pm 0.464 a$ \\
\hline \multirow{3}{*}{10} & 0 & $9.976 \pm 0.345 \mathrm{de}$ & $8.488 \pm 1.051 \mathrm{f}$ & $29.190 \pm 0.226 \mathrm{e}$ & $43.833 \pm 0.817 \mathrm{f}$ & $10.883 \pm 0.265 \mathrm{~d}$ & $12.365 \pm 0.128 b$ & $10.698 \pm 0.173 \mathrm{f}$ & $3.637 \pm 0.196 \mathrm{~d}$ \\
\hline & 100 & $9.870 \pm 0.503 \mathrm{e}$ & $11.800 \pm 0.174 \mathrm{~cd}$ & $40.680 \pm 0.832 \mathrm{~d}$ & $56.380 \pm 2.614 \mathrm{~d}$ & $11.656 \pm 0.780 \mathrm{~cd}$ & $8.896 \pm 0.222 \mathrm{~d}$ & $13.571 \pm 0.149 \mathrm{~d}$ & $7.036 \pm 0.344 b$ \\
\hline & 200 & $12.301 \pm 0.086 \mathrm{~b}$ & $10.215 \pm 0.186 \mathrm{e}$ & $42.523 \pm 0.599 \mathrm{~d}$ & $51.283 \pm 5.323 \mathrm{e}$ & $17.643 \pm 0.663 \mathrm{a}$ & $12.421 \pm 0.362 b$ & $14.421 \pm 0.265 \mathrm{c}$ & $6.545 \pm 0.056 c$ \\
\hline \multirow{3}{*}{20} & 0 & $10.435 \pm 0.132 \mathrm{de}$ & $10.108 \pm 0.190 \mathrm{e}$ & $39.895 \pm 2.159 \mathrm{~d}$ & $70.497 \pm 1.813 \mathrm{~b}$ & $12.556 \pm 0.805 c$ & $13.316 \pm 0.477 \mathrm{a}$ & $12.624 \pm 0.408 \mathrm{e}$ & $8.362 \pm 0.128 \mathrm{a}$ \\
\hline & 100 & $12.233 \pm 0.175 b$ & $12.846 \pm 0.397 b$ & $49.190 \pm 1.485 c$ & $57.293 \pm 0.395 \mathrm{~d}$ & $16.660 \pm 0.294 a$ & $11.358 \pm 0.174 c$ & $10.238 \pm 0.204 \mathrm{~g}$ & $8.767 \pm 0.371 \mathrm{a}$ \\
\hline & 200 & $10.552 \pm 0.397 \mathrm{~d}$ & $12.158 \pm 0.397 \mathrm{bc}$ & $50.104 \pm 0.226 c$ & $53.240 \pm 0.450 \mathrm{de}$ & $17.205 \pm 0.582 \mathrm{a}$ & $13.591 \pm 0.224 \mathrm{a}$ & $14.519 \pm 0.098 \mathrm{c}$ & $6.676 \pm 0.098 b c$ \\
\hline
\end{tabular}

Each value is the mean of three replicates. Means followed by same small letters in the same column are not significantly different at $P \leq 0.05$.
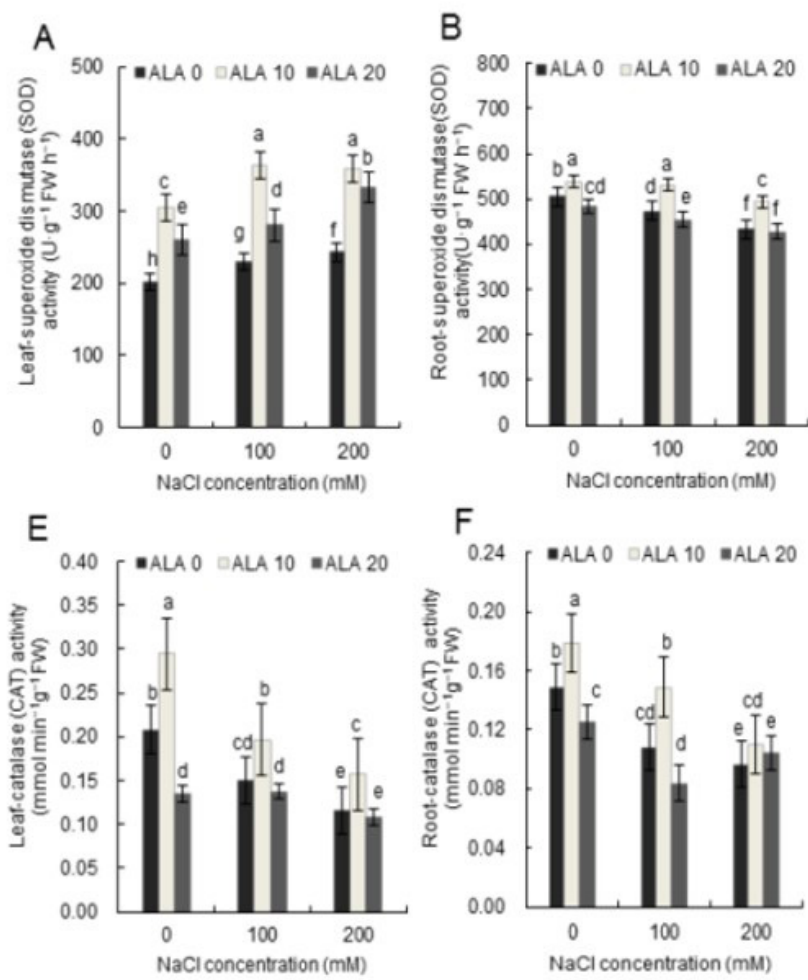
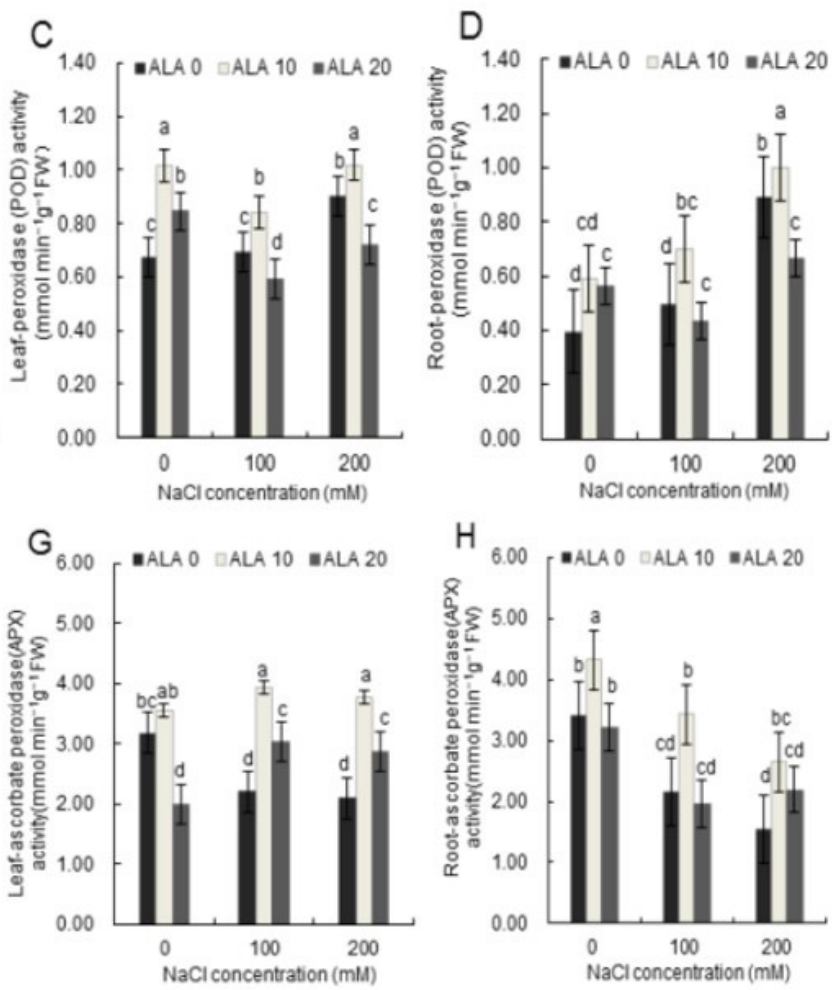

Figure 1. Effects of 5-aminolevulinic acid on the antioxidant enzyme activities in S. miltiorrhiza under different salinity stresses: A Leaf-superoxide dismutase (SOD); B Root-superoxide dismutase (SOD); C Leaf-peroxidase (POD); D Root-peroxidase (POD) activity; E Leaf-catalase (CAT); F Root-catalase (CAT); and G Leaf-ascorbate peroxidase (APX); H Root-ascorbate peroxidase (APX). Values are the means of three independent replications $\pm \mathrm{SE}$. 
increase of salt concentration from 100 to $200 \mathrm{mM}$ (Figure 1EF), however, these trends were not significant in APX activities (Figure $1 \mathrm{GH}$ ). However, the impact of salinity on POD activities was significant only under higher concentrations of salinity $(200 \mathrm{mM})$, which significantly increased POD activity (Figure 1CD), in both leaves and roots tissues of S. miltiorrhiza. SOD activities were significantly enhanced in leaves with the salinity increased from 100 to $200 \mathrm{mM}$, however, the trends in roots were opposite (Figure 1AB). ALA $\left(10 \mathrm{mg} \mathrm{L}^{-1}\right)$ could significantly regulated different antioxidant enzyme activities in $S$. miltiorrhiza tissues under different salt treatments. For instance, compared with $200 \mathrm{mM}$ salinity stress alone, $10 \mathrm{mg} \mathrm{L}^{-1}$ of ALA significantly upregulated POD activity in leaves and roots of $S$. miltiorrhiza by $13.11 \%$ and $12.49 \%$, respectively. Similarly, under $200 \mathrm{mM}$ salinity treatment alone, $10 \mathrm{mg} \mathrm{L}^{-1}$ ALA application significantly upregulated CAT by $36.42 \%$ and $14.13 \%$, and APX by $79.22 \%$ and $72.22 \%$ in the leaves and roots of S. miltiorrhiza, respectively. Noticeably, higher dosage of ALA concentration $\left(20 \mathrm{mg} \mathrm{L}^{-1}\right)$ significantly depressed the activities of antioxidant enzymes in leaf tissues under salinity stresses (100 or $200 \mathrm{mM}$ ). It was obvious that an appropriate concentration of ALA (10 mg $\left.\mathrm{L}^{-1}\right)$ could promote antioxidant enzyme activities under salinity condition, but its higher concentration i.e. $20 \mathrm{mg} \mathrm{L}^{-1} \mathrm{ALA}$, had a negative effect on antioxidant enzyme activities under salinity.

\subsection{Expression profiles of key genes}

Higher level $(200 \mathrm{mM})$ of salinity in the growth media significantly inhibited the expression of genes regulating antioxidant enzyme i.e. CSD1 and key genes associated with secondary metabolites (DXS1, C4H, GGPPS, HMGR). In contrast, ALA upregulated the expression of genes associated with stress response (MYB36) in S. miltiorrhiza root tissues (Figure 2). Meanwhile, $10 \mathrm{mg} \mathrm{L}^{-1}$ ALA significantly upregulated most of the studied genes in S. miltiorrhiza except $H M G R$, $P A L$ and MYB39. For instance, FSD1 and MSD2 genes were significantly upregulated by $211.24 \%$ and $224.89 \%$, respectively, but $H M G R$ was significantly downregulated by $11.95 \%$ in $S$. miltiorrhiza roots, as compared with the control. The analysis of gene expression data showed that $10 \mathrm{mg} \mathrm{L}^{-1}$ ALA was relatively more effective in promoting the expression of key genes under $200 \mathrm{mM}$ salinity stress, particularly the expression of genes such as FSD1, GGPPS, HMGR and PAL was increased by $249.31 \%$, $255.65 \%, 345.05 \%$ and $304.81 \%$ in the roots of S. miltiorrhiza, respectively. We concluded that ALA $\left(10 \mathrm{mg} \mathrm{L}^{-1}\right)$ protected $S$. miltiorrhiza plants from salt-induced toxicity by decreasing oxidative stress and by modulating the expression of ROS scavenging and secondary metabolites and stress-related genes in S. miltiorrhiza.

\section{Discussion}

\subsection{ALA mediated modulation of secondary metabolites and stress responsive genes}

Secondary metabolites have important adaptive and defense roles in plant interactions with the environment, especially for abiotic stresses (Akula \& Ravishankar, 2011). Tanshinone and Rosmarinic acid are the main secondary metabolites of $S$.

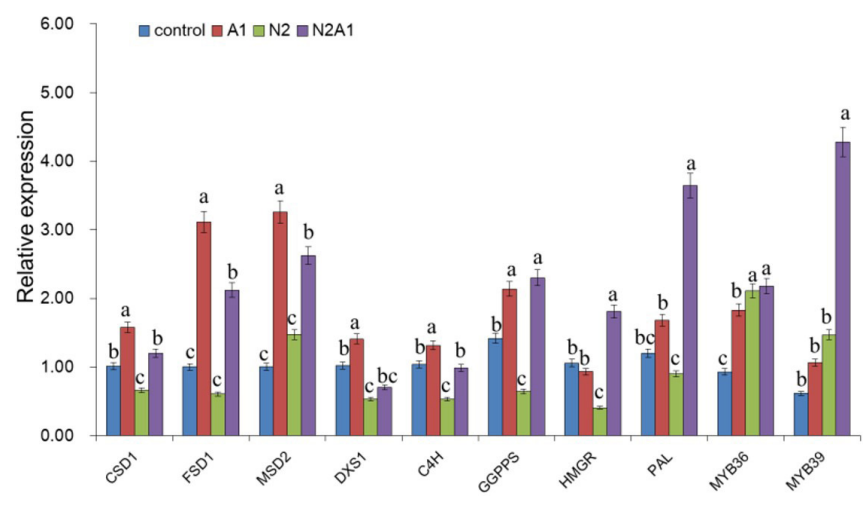

Figure 2. Effects of 5-aminolevulinic acid on the expressions of key secondary metabolites genes in S. miltiorrhiza under different salinity stresses. Relative expression levels of these genes were examined in the tested plants by qRT-PCR analysis. Control; A1, treatment with $10 \mathrm{mg} \mathrm{L}^{-1}$ ALA alone; N2, treated with $\mathrm{NaCl}(200 \mathrm{mM})$ alone; and N2A1, treatment with both $\mathrm{NaCl}(200 \mathrm{mM})$ and $10 \mathrm{mg} \mathrm{L}^{-1}$ ALA. Means followed by the same letters were not significantly different at $P \leq 0.05$.

miltiorrhiza, and could limit salinity induced intercellular ROS production (Gao et al., 2014; Zhang et al., 2014). ALA strongly stimulated the expression levels of DXS, GGPPS, HMGR and other key genes in tanshinone metabolic pathway (Kai et al., 2011). The other related secondary metabolic pathway gens, like C4H, PAL, 4CL were involved in the rosmarinic acid metabolic pathway in previous studies (Song \& Wang, 2009; Huang et al., 2008). In addition, it has been reported that exogenous growth regulators can modify the expression of key genes in secondary metabolic pathways,for example, methyl jasmonate can induce the expression of $C 4 H, P A L$, etc in S. miltiorrhiza (Xiao et al., 2009). In this study, exogenous ALA could significantly induced some key genes in metabolic pathways, such as DXS1,C4H and GGPPS (Figure 2). We found that the gene expressions of DXS1, C4H, GGPPS and HMGR were significantly down-regulated under salt condition, indicating the negative effects of salt stress on S. miltiorrhiza root tissue. Similarly, ALA significantly upregulated the expression of $C 4 H, G G P P S, H M G R$ and PAL genes under salt condition. Interestingly, the expression of $P A L$ gene was significantly up-regulated after ALA and salt treatment, indicating that ALA has a positive regulatory effect on $P A L$. However, ALA alone or salt alone had no significant effect on $P A L$. These results suggest that ALA can affect the metabolic pathway of $S$. miltiorrhiza to adapt to salt conditions.

MYB transcription factor is one of the largest members of the plant transcription factor family. It plays an important role in the regulation of plant secondary metabolism, response of hormones and environmental factors, and organ morphogenesis. It can bind to cis-acting elements upstream of stress resistance gene and specifically regulate the expression of the gene in plants, which plays an important role in abiotic stress breeding such as drought resistance, salt tolerance and temperature tolerance (Li et al., 2019b). According to Zhang et al. (2020), R2R3-MYB transcription factor AtMYB49 activates cuticle deposition and antioxidant defense, contributing to salt tolerance of Arabidopsis thaliana. Similarly Wu et al. (2019) verified that $Z m M Y B 3 R$ could increase the activities of CAT, POD and SOD, enhance the 
sensitivity to ABA, and significantly enhance the regulation of stomatal opening, and enhance the tolerance to drought and salt stress. Similarly, it has reported overexpressed SmMYB36 could regulate metabolic pathways and promote the accumulation of metabolites (Ding et al., 2017). Recently, Wang et al. (2020) found that MYB36 regulates MYB39 to stimulate root development in Arabidopsis thaliana. In this study, we found that exogenous ALA and salt could independently up-regulate the expression of MYB36, while applying ALA under salt conditions had no significant effect on the expression of MYB36, but stimulated the significant up-regulation of MYB39 in S. miltiorrhiza root tissues (Figure 2). There may be some related regulatory relationships between MYB36 and MYB39 in S. miltiorrhiza root tissues under abiotic stress, which warrants further investigations.

\subsection{ALA enhances salinity tolerance by alleviating oxidative damages in S. miltiorrhiza}

Salt stress decreases the accumulation and translocation of key mineral ions such as N, K, etc. aggravates osmotic pressure and ionic toxicity (Ahanger \& Agarwal, 2017; Ahanger et al., 2019a). The delicate balance of ROS disturbed, when plants are exposed to adverse conditions such as salinity, as they accelerate intra and intercellular ROS levels, leading to ROS burst and injury to membranous structures such as proteins and nucleic acids (Sharma et al., 2012; Ahanger et al., 2019b). To detoxify unregulated ROS, plants modify antioxidant enzymes and their transcript levels, which has been observed in present study (Figure 1). Among these, SOD is a major enzyme, which can effectively decrease oxidative stress by eliminating excessive ROS in plant tissues (Han et al., 2020). For instance, SOD enzyme, as a key enzyme in plant antioxidant system, it converts highly reactive $\mathrm{OH}^{-}$radical and superoxide $\left(\mathrm{O}^{-}\right)$to less toxic $\mathrm{H}_{2} \mathrm{O}_{2}$. Lu et al. (2020) found that soybean SOD gene may play a positive role in response to alkaline stress. Han et al. (2020) suggested that SmSODs had different responses to cold, salt, drought, heavy metals and plant hormones in S. miltiorrhiza. In this study, S. miltiorrhiza root tissue under the application of $10 \mathrm{mg} \mathrm{L}^{-1}$ ALA significantly increased SOD activity under salt stress (Figure 1B). CSD1, FSD1 and MSD2 genes expression were also up-regulated (Figure 2). These results indicated that ALA application play a complementary role in the maintenance of total SOD activity and the detoxification of ROS in S. miltiorrhiza under stress conditions.

It is established that 1-glutamic acid is catalyzed into 1-Glutamyl-tRNA and 1-Glutamic acid-1-semialdehyde under the catalysis of enzymes glutamyl-tRNA synthetase and glutamyltRNA reductase, severally. Whereafter, under the catalysis of enzyme l-glutamate1-semialdehyde aminotransferase, 1-Glutamic acid-1-semialdehyde converted to ALA (Rhaman et al., 2021). And ALA has been found as a ROS scavenges in plants. For example, ALA significantly reduced $\mathrm{H}_{2} \mathrm{O}_{2}$ content in rice and protected chlorophyll from salt injury by modifying antioxidant enzymes (Nunkaew et al., 2014). Similar positive effect of ALA spraying on cucumber leaves has been observed under salt stressed environments (Zhen et al., 2012). In this study, ALA protected $S$. miltiorrhiza plants from salt injury by adjusting antioxidant enzymes. For example, $10 \mathrm{mg} \mathrm{L}^{-1}$ ALA increased the activities of
CAT and APX enzymes under high-salt (200 mM) conditions (Figure 1EFGH). In addition, except for ${ }^{-} \mathrm{OH}$ in leaves, the content of other ROS significantly decreased, indicating that ALA could effectively improve the activity of some antioxidant enzymes to overcome oxidative damage (Table 4). In addition, we found that $10 \mathrm{mg} \mathrm{L}^{-1}$ of ALA as an optimum concentration, while higher ALA concentration could increase ROS production and exacerbate oxidative damage in plants as suggested by Rhaman et al. (2021).

\subsection{The key regulatory mechanisms of ALA in S. miltiorrhiza under the salinity stress}

It is well-known that salt stress degrades photosynthetic pigments, reduces $\mathrm{CO}_{2}$ fixation, and damage chloroplast ultrastructure and photosynthetic enzymes, impeding photosynthetic systems. (Rhaman et al., 2021). Exogenous ALA at an appropriate concentration can increase chlorophyll content and activated the antioxidant enzymes to cope with abiotic stress in rice and cucumber. (Nunkaew et al., 2014; Wu et al., 2018). The exogenous ALA can also decrease the MDA content, and ROS production in rapeseed, cucumber and peach under salt stress (Naeem et al., 2011; Zhen et al., 2012; Ye et al., 2016). In addition, ALA application in salt-stressed cucumber plant up-regulated the expressions of CAT, APX, Mg-chelatase, and protochlorophyllide oxidoreductase (POR) genes (Zhen et al., 2012; Wu et al., 2018). In conclusion, to promote plant growth and development, ALA application can alleviate salt stress in plants by promoting photosynthetic system, improving antioxidant enzyme system, reducing ROS content and inducing key stress related metabolic genes.

We found that salinity significantly inhibited growth and biomass accumulation of S. miltiorrhiza (Table 1). No significant variations in plant height, fresh weight of leaves for root length, fresh/dry weights of roots of S. miltiorrhiza under 100 and $200 \mathrm{mM}$ of $\mathrm{NaCl}$, which may be because the plants have experienced maximum growth inhibition within the studied time frame. Salt-induced structural damage to chlorophyll could inhibit carbon assimilation and biomass accumulation in plants. ALA, on the other hand, restored leaf chlorophyll, which was consistent with Naeem et al. (2010) study. This chlorophyll restoration could be associated with positive impact of ALA on chloroplast biosynthesis. Similarly, ALA protected carotenoids in S. miltiorrhiza leaves from salt-induced photooxidation by dissipating the excessive excitation energy (Mittler, 2002). The application of ALA could effectively increase SOD enzyme activity. Meanwhile, the expressions of three genes (Figure 2), CSD1, FSD1 and MSD2 in S. miltiorrhiza roots, were significantly down regulated under salinity stress. There are studies which suggest that variation in SOD homologous i.e. $M n-S O D$ and $\mathrm{Cu} / \mathrm{Zn}-\mathrm{SOD}$ in sensing and eliminating ROS in plant cells (Jebara et al., 2005; Ueda et al., 2013). SOD enzyme may play complementary roles in maintaining total SOD enzyme activity and ROS in S. miltiorrhiza under salinity stress conditions. In addition, the increased oxidative toxicity in S. miltiorrhiza under salinity stress possibility arise from the reduced activities of POD, CAT and APX. CAT can eliminate ROS such as $\mathrm{H}_{2} \mathrm{O}_{2}$ by converting it into $\mathrm{H}_{2} \mathrm{O}$, and reduction in CAT may affect ROS 
effectiveness in plants, as detected in S. miltiorrhiza. ALA also promoted POD activity, which has an important role in salinity tolerance in the tissues of $S$. miltiorrhiza. Overall, antioxidant data analysis indicated that ALA pretreatment protected $S$. miltiorrhiza against salinity stress by reducing oxidative stress and elevating antioxidant enzyme activities. A pivotal precursor of biosynthesis of metabolites such as tetrapyrrole, ALA can induce plant growth and stresses tolerance even when applied in low concentrations. Our study indicated that ALA could enhance aboveground biomass accumulation, photosynthesis and antioxidant enzyme activity of S. miltiorrhiza to reduce salinity injury. ALA had a certain promoting effect on alleviating S. miltiorrhiza under salinity stress. However, the mechanism of how ALA improves S. miltiorrhiza resistance to salinity stress needs further investigations.

\section{Conclusion}

Our study indicated that salinity stress can impair growth and biomass production of $S$. miltiorrhiza seedlings via oxidative injury, because the suppressed antioxidant enzyme system is not sufficient enough to confront with the increased ROS under salt stresses, in S. miltiorrhiza. ALA restored the growth of salt stressed plants by upregulating antioxidant enzymes and reducing membrane peroxidation. Induction of CSD1, GGPPS and other stress and secondary metabolic pathway genes indicated a high adaptative response against salinity stress after ALA application. These results suggested that ALA can effectively alleviate salinity stress through promoting antioxidant defense system, reducing ROS generation, and regulating expression profiling of stress responsive genes.

\section{Abbreviations}

APX: Ascorbate peroxidase. C4H: Cinnamic acid 4-hydroxylase. CAT: Catalase. CSD: Copper/zinc superoxide dismutase. DXS: 1-deoxy-D-xylulose 5-phosphate synthase. FSD: Fe superoxide dismutase. GGPPS: Geranylgeranyl diphosphate synthase. HMGR: 3-Hydroxy-3-methylglutaryl CoA reductase. MDA: Malondialdehyde. MSD: Manganese Superoxide dismutase. MYB R2R3-MYB: transcription factor. PAL: Phenylalanine ammonia-lyase. POD: Peroxidase. ROS: Reactive oxygen species. SOD: Superoxide dismutase.

\section{Conflict of interest}

The authors declare no conflict of interest. The authors declare that they have no known competing financial interests or personal relationships that could have appeared to influence the work reported in this paper.

\section{Author contributions}

X.L and L.X conceived the original research plan. X.L, J.J.L and J.M.P conducted the experiment. X.L and J.M.P generated the figures. X.L and J.J.L wrote the article with contributions from all authors. F.I, U.N and L.X revised the manuscript. Z.N.H, J.Y.S and Y.B.Q supervise the experiment. J.Y.S, Y.B.Q and L.X supported the experiment. All authors revised and approved the manuscript.

\section{Acknowledgements}

This work was supported by the National Natural Science Foundation of China (31871694, 31800255), and the Fundamental Research Funds of Zhejiang Sci-Tech University (2020Q022, 14042216-Y).

\section{References}

Abogadallah, G. M. (2010). Antioxidative defense under salt stress. Plant Signaling \& Behavior, 5, 369-374.

Aebi, H. (1984). Catalase in vitro. Methods in Enzymology, 105, 121-126. http://dx.doi.org/10.1016/S0076-6879(84)05016-3. PMid:6727660.

Ahanger, M. A., \& Agarwal, R. M. (2017). Salinity stress induced alterations in antioxidant metabolism and nitrogen assimilation in wheat (Triticum aestivum $\mathrm{L}$ ) as influenced by potassium supplementation. Plant Physiology and Biochemistry, 115, 449-460.

Ahanger, M. A., Qin, C., Begum, N., Maodong, Q., Dong, X. X., ElEsawi, M., El-Sheikh, M. A., Alatar, A. A., \& Zhang, L. (2019a). Nitrogen availability prevents oxidative effects of salinity on wheat growth and photosynthesis by up-regulating the antioxidants and osmolytes metabolism, and secondary metabolite accumulation. BMC Plant Biology, 19(1), 479. http://dx.doi.org/10.1186/s12870019-2085-3. PMid:31703619.

Ahanger, M. A., Qin, C., Maodong, Q., Dong, X. X., Ahmad, P., Abd Allah, E. F., \& Zhang, L. (2019b). Spermine application alleviates salinity induced growth and photosynthetic inhibition in Solanum lycopersicum by modulating osmolyte and secondary metabolite accumulation and differentially regulating antioxidant metabolism. Plant Physiology and Biochemistry, 144, 1-13. http://dx.doi.org/10.1016/j. plaphy.2019.09.021. PMid:31542655.

Akula, R., \& Ravishankar, G. A. (2011). Influence of abiotic stress signals on secondary metabolites in plants. Plant Signaling \& Behavior, 6(11), 1720-1731. http://dx.doi.org/10.4161/psb.6.11.17613. PMid:22041989.

Ali, B., Gill, R. A., Yang, S., Gill, M. B., Farooq, M. A., Liu, D., Daud, M. K., Ali, S., \& Zhou, W. (2015). Regulation of cadmium-induced proteomic and metabolic changes by 5 -aminolevulinic acid in Leaves of Brassica napus L. PLoS One, 10(4), e0123328. http://dx.doi. org/10.1371/journal.pone.0123328. PMid:25909456.

Ali, B., Huang, C. R., Qi, Z. Y., Daud, M. K., Geng, X. X., Liu, H. B., \& Zhou, W. J. (2013a). 5-aminolevulinic acid ameliorates cadmiuminduced morphological, biochemical and ultrastructural changes in seedlings of oilseed rape. Environmental Science and Pollution Research International, 20(10), 7256-7267. http://dx.doi.org/10.1007/ s11356-013-1735-5. PMid:23625120.

Ali, B., Tao, Q. J., Zhou, Y. F., Gill, R. A., Ali, S., Rafiq, M. T., Xu, L. \& Zhou, W. J. (2013c). 5-Aminolevulinic acid mitigates the cadmiuminduced changes in Brassica napus as revealed by the biochemical and ultra-structural evaluation of roots. Ecotoxicology and Environmental Safety, 92, 271-280. http://dx.doi.org/10.1016/j.ecoenv.2013.02.006. PMid:23490193.

Ali, B., Wang, B., Ghani, M. A., Hayat, M. T., Yang, C., Xu, L., \& Zhou, W. J. (2013b). 5-aminolevulinic acid ameliorates the growth, photosynthetic gas exchange capacity and ultrastructural changes under cadmium stress in Brassica napus L. Journal of Plant Growth Regulation, 32(3), 604-614. http://dx.doi.org/10.1007/s00344-013-9328-6.

Ali, B., Xu, X., Gill, R. A., Yang, S., Ali, S., Tahir, M., \& Zhou, W. (2014). Promotive role of 5-aminolevulinic acid on mineral nutrients and antioxidative defense system under lead toxicity in Brassica napus. Industrial Crops and Products, 52, 617-626. http://dx.doi.org/10.1016/j. indcrop.2013.11.033. 
Ding, K., Pei, T., Bai, Z., Jia, Y., Ma, P., \& Liang, Z. (2017). SmMYB36, a Novel R2R3-MYB Transcription factor, enhances tanshinone accumulation and decreases phenolic acid content in Salvia miltiorrhiza hairy roots. Scientific Reports, 7(1), 5104. http://dx.doi. org/10.1038/s41598-017-04909-w. PMid:28698552.

Gao, W., Sun, H. X., Xiao, H., Cui, G., Hillwig, M. L., Jackson, A., Wang, X., Shen, Y., Zhao, N., Zhang, L., Wang, X. J., Peters, R. J., \& Huang, L. (2014). Combining metabolomics and transcriptomics to characterize tanshinone biosynthesis in Salvia miltiorrhiza. BMC Genomics, 15, 73. http://dx.doi.org/10.1186/1471-2164-15-73. PMid:24467826.

Gengmao, Z., Quanmei, S., Yu, H., Shihui, L., \& Changhai, W. (2014). The physiological and biochemical responses of a medicinal plant (Salvia miltiorrhiza L) to stress caused by various concentrations of NaCl. PLoS One, 9(2), e89624. http://dx.doi.org/10.1371/journal. pone.0089624. PMid:24586918.

Guo, X., Niu, J., \& Cao, X. (2018). Heterologous expression of Salvia miltiorrhiza MicroRNA408 enhances tolerance to salt stress in Nicotiana benthamiana. International Journal of Molecular Sciences, 19(12), 3985. http://dx.doi.org/10.3390/ijms19123985. PMid:30544912.

Halliwell, B., Gutteridge, J. M., \& Aruoma, O. I. (1987). The deoxyribose method: a simple "test-tube" assay for determination of rate constants for reactions of hydroxyl radicals. Analytical Biochemistry, 165(1), 215-219. http://dx.doi.org/10.1016/0003-2697(87)90222-3. PMid:3120621.

Han, L. M., Hua, W. P., Cao, X. Y., Yan, J. A., Chen, C., \& Wang, Z. Z. (2020). Genome-wide identification and expression analysis of the superoxide dismutase (SOD) gene family in Salvia miltiorrhiza. Gene, 742, 144603. http://dx.doi.org/10.1016/j.gene.2020.144603. PMid:32198126.

Hao, P. P., Jiang, F., Chen, Y. G., Yang, J., Zhang, K., Zhang, M. X., Zhang, C., Zhao, Y. X., \& Zhang, Y. (2015). Evidence for traditional chinese medication to treat cardiovascular disease. Nature Reviews. Cardiology, 12(6), 374. http://dx.doi.org/10.1038/nrcardio.2014.177-c2. PMid:25917155.

Huang, B., Duan, Y., Yi, B., Sun, L., Lu, B., Yu, X., Sun, H., Zhang, H., \& Chen, W. (2008). Characterization and expression profiling of cinnamate 4-hydroxylase gene from Salvia miltiorrhiza in rosmarinic acid biosynthesis pathway. Russian Journal of Plant Physiology: a Comprehensive Russian Journal on Modern Phytophysiology, 55(3), 390-399. http://dx.doi.org/10.1134/S1021443708030163.

Huang, T., Yang, X., Ji, J., Wang, Q., Wang, H., \& Dong, Z. (2020). Inhibitory effects of tanshinone IIA from Salvia miltiorrhiza Bge on human bladder cancer BIU-87 cells and xenograft in nude mice. Food Science and Technology, 40(1), 209-214. http://dx.doi. org/10.1590/fst.38818.

Islam, F., Xie, Y., Farooq, M. A., Wang, J., Yang, C., Gill, R. A., Zhu, J. \& Zhou, W. (2018). Salinity reduces 2, 4-D efficacy in Echinochloa crusgalli by affecting redox balance, nutrient acquisition, and hormonal regulation. Protoplasma, 255(3), 785-802. http://dx.doi. org/10.1007/s00709-017-1159-z. PMid:29151143.

Jebara, S., Jebara, M., Limam, F., \& Aouani, M. E. (2005). Changes in ascorbate peroxidase, catalase, guaiacol peroxidase and superoxide dismutase activities in common bean (Phaseolus vulgaris) nodules under salinity stress. Journal of Plant Physiology, 162(8), 929-936. http://dx.doi.org/10.1016/j.jplph.2004.10.005. PMid:16146319.

Jiang, M., \& Zhang, J. (2001). Effect of abscisic acid on active oxygen species, antioxidative defence system and oxidative damage in leaves of maize seedlings. Plant \& Cell Physiology, 42(11), 1265-1273. http:// dx.doi.org/10.1093/pcp/pce162. PMid:11726712.

Kai, G., Xu, H., Zhou, C., Liao, P., Xiao, J., Luo, X., You, L., \& Zhang, L. (2011). Metabolic engineering tanshinone biosynthetic pathway in Salvia miltiorrhiza hairy root cultures. Metabolic Engineering, 13(3), 319-327. http://dx.doi.org/10.1016/j.ymben.2011.02.003. PMid:21335099.

Khan, M. A., Asaf, S., Khan, A. L., Adhikari, A., Jan, R., Ali, S., Imran, M., Kim, K. M., \& Lee, I. J. (2019). Halotolerant rhizobacterial strains mitigate the adverse effects of nacl stress in soybean seedlings. BioMed Research International, 2019, 9530963. http://dx.doi. org/10.1155/2019/9530963. PMid:31886270.

Li, J. J., Yang, C., Liu, H., Cao, M. T., Yan, G., Si, P., Zhou, W., \& Xu, L. (2019a). 5-Aminolevolinic acid enhances sunflower resistance to Orobanche cumana (broomrape). Industrial Crops and Products, 140, 111467. http://dx.doi.org/10.1016/j.indcrop.2019.111467.

Li, J., Han, G., Sun, C., \& Sui, N. (2019b). Research advances of MYB transcription factors in plant stress resistance and breeding. Plant Signaling \& Behavior, 14(8), 1613131. http://dx.doi.org/10.1080/1 5592324.2019.1613131. PMid:31084451.

Lichtenthaler, H. K. (1987). Chlorophylls and carotenoids: pigments of photosynthetic biomemranes. Methods in Enzymology, 148, 350-382. http://dx.doi.org/10.1016/0076-6879(87)48036-1.

Liu, J., \& Shi, D. C. (2010). Photosynthesis, chlorophyll fluorescence, inorganic ion and organic acid accumulations of sunflower in responses to salt and salt-alkaline mixed stress. Photosynthetica, 48(1), 127-134. http://dx.doi.org/10.1007/s11099-010-0017-4.

Livak, K. J., \& Schmittgen, T. D. (2001). Analysis of relative gene expression data using realtime quantitative PCR and the $2^{-\Delta \Delta \mathrm{Ct}}$ method. Methods, 25(4), 402-408. http://dx.doi.org/10.1006/ meth.2001.1262. PMid:11846609.

Lu, W., Duanmu, H., Qiao, Y., Jin, X., Yu, Y., Yu, L., \& Chen, C. (2020). Genome-wide identification and characterization of the soybean SOD family during alkaline stress. PeerJ, 8, e8457. http://dx.doi. org/10.7717/peerj.8457. PMid:32071807.

Mittler, R. (2002). Oxidative stress, antioxidants and stress tolerance. Trends in Plant Science, 7(9), 405-410. http://dx.doi.org/10.1016/ S1360-1385(02)02312-9. PMid:12234732.

Naeem, M. S., Rasheed, M., Liu, D., Jin, Z. L., Ming, D. F., Yoneyama, K., Takeuchi, Y., \& Zhou, W. J. (2011). 5-Aminolevulinic acid ameliorates salinity-induced metabolic,water-related and biochemical changes in Brassica napus L. Acta Physiologiae Plantarum, 33, 517-528. http:// dx.doi.org/10.1007/s11738-010-0575-x.

Naeem, M., Jin, Z. L., Wan, G. L., Liu, D., Liu, H. B., Yoneyama, K., \& Zhou, W. J. (2010). 5-aminolevulinic acid improves photosynthetic gas exchange capacity and ion uptake under salinity stress in oilseed rape (Brassica napus L). Plant and Soil, 332(1), 405-415. http:// dx.doi.org/10.1007/s11104-010-0306-5.

Nakano, Y., \& Asada, K. (1981). Hydrogen-peroxide is scavenged by ascorbate-specific peroxidase in spinach-chloroplasts. Plant \& Cell Physiology, 22, 867-880.

Nunkaew, T., Kantachote, D., Kanzaki, H., Nitoda, T., \& Ritchie, R. J. (2014). Effects of 5-aminolevulinic acid (ALA)-containing supernatants from selected Rhodopseudomonas palustris strains on rice growth under $\mathrm{NaCl}$ stress, with mediating effects on chlorophyll, photosynthetic electron transport and antioxidative enzymes. Electronic Journal of Biotechnology, 17(1), 19-26. http:// dx.doi.org/10.1016/j.ejbt.2013.12.004.

Rhaman, M. S., Imran, S., Karim, M. M., Chakrobortty, J., Mahamud, M. A., Sarker, P., Tahjib-Ul-Arif, M., Robin, A. H. K., Ye, W., Murata, Y., \& Hasanuzzaman, M. (2021).5-aminolevulinic acid-mediated plant adaptive responses to abiotic stress. Plant Cell Reports, 40(8), 14511469. http://dx.doi.org/10.1007/s00299-021-02690-9. PMid:33839877. 
Sharma, P., Jha, A. B., Dubey, R. S., \& Pessarakli, M. (2012). Reactive oxygen species, oxidative damage, and antioxidative defense mechanism in plants under stressful conditions. Le Journal de Botanique, 2012, 1-26. http://dx.doi.org/10.1155/2012/217037.

Shi, M., Huang, F. F., Deng, C. P., Wang, Y., \& Kai, G. Y. (2018). Bioactivities, biosynthesis and biotechnological production of phenolic acids in Salvia miltiorrhiza. Critical Reviews in Food Science and Nutrition, 59(6), 953-964. http://dx.doi.org/10.1080/10408398.2018.147417 0. PMid:29746788.

Song, J., \& Wang, Z. (2009). Molecular cloning, expression and characteri-zation of a phenylalanine ammonia-lyase gene (SmPAL1) from Salvia miltiorrhiza. Molecular Biology Reports, 36(5), 939-952. http://dx.doi.org/10.1007/s11033-008-9266-8. PMid:18454352.

Tufail, A., Li, H., Naeem, A., \& Li, T. X. (2018). Leaf cell membrane stability-based mechanisms of zinc nutrition in mitigating salinity stress in rice. Plant Biology, 20(2), 338-345. http://dx.doi.org/10.1111/ plb.12665. PMid:29148143.

Ueda, Y., Uehara, N., Sasaki, H., Kobayashi, K., \& Yamakawa, T. (2013). Impacts of acute ozone stress on superoxide dismutase (SOD) expression and reactive oxygen species (ROS) formation in rice leaves. Plant Physiology and Biochemistry, 70, 396-402. http://dx.doi. org/10.1016/j.plaphy.2013.06.009. PMid:23831949.

Wang, C., Wang, H., Li, P., Li, H., Xu, C., Cohen, H., Aharoni, A., \& $\mathrm{Wu}, \mathrm{S}$. (2020). Developmental programs interact with abscisic acid to coordinate root suberization in Arabidopsis. The Plant Journal, 104(1), 241-251. http://dx.doi.org/10.1111/tpj.14920. PMid:32645747.

Wang, L. J., Jiang, W. B., \& Huang, B. J. (2004). Promotion of 5 -aminolevulinic acid on photosynthesis of melon (Cucumis melo) seedlings under low light and chilling stress conditions. Physiologia Plantarum, 121(2), 258-264. http://dx.doi.org/10.1111/j.00319317.2004.00319.x. PMid:15153193.

Watanabe, K., Tanaka, T., Hotta, Y., Kuramochi, H., \& Takeuchi, Y. (2000). Improving salt tolerance of cotton seedlings with 5-aminolevulinic acid. Plant Growth Regulation, 32(1), 97-101. http://dx.doi.org/10.1023/A:1006369404273.

Wu, J., Jiang, Y., Liang, Y., Chen, L., Chen, W., \& Cheng, B. (2019). Expression of the maize MYB transcription factor ZmMYB3R enhances drought and salt stress tolerance in transgenic plants. Plant Physiology and Biochemistry, 137, 179-188. http://dx.doi. org/10.1016/j.plaphy.2019.02.010. PMid:30798172.

Wu, Y., Jin, X., Liao, W., Hu, L., Dawuda, M. M., Zhao, X., Tang, Z., Gong, T., \& Yu, J. (2018). 5-aminolevulinic acid (ALA) alleviated salinity stress in cucumber seedlings by enhancing chlorophyll synthesis pathway. Frontiers in Plant Science, 9, 635. http://dx.doi. org/10.3389/fpls.2018.00635. PMid:29868088.

Xiao, Y., Gao, S., Di, P., Chen, J., Chen, W., \& Zhang, L. (2009). Methyl jasmonate dramatically enhances the accumulation of phenolic acids in Salvia miltiorrhiza hairy root cultures. Physiologia Plantarum,
137(1), 1-9. http://dx.doi.org/10.1111/j.1399-3054.2009.01257.x. PMid:19570133.

Xing, B., Yang, D., Liu, L., Han, R., Sun, Y., \& Liang, Z. (2018). Phenolic acid production is more effectively enhanced than tanshinone production by methyl jasmonate in S. miltiorrhiza hairy roots. Plant Cell, Tissue and Organ Culture, 134(1), 119-129. http://dx.doi. org/10.1007/s11240-018-1405-X.

Xu, D., Gui, C., Zhao, H., \& Liu, F. (2021). Cryptotanshinone protects hippocampal neurons against oxygen-glucose deprivation-induced injury through the activation of Nrf2/HO-1 signaling pathway. Food Science and Technology, Ahead of print. http://dx.doi.org/10.1590/ fst. 46521.

Xu, L., Zeng, W., Li, J., Liu, H., Yan, G., Si, P., Yang, C., Shi, Y., He, Q., \& Zhou, W. (2019). Characteristics of membrane-bound fatty acid desaturase (FAD) genes in Brassica napus L. and their expressions under different cadmium and salinity stresses. Environmental and Experimental Botany, 162, 144-156. http://dx.doi.org/10.1016/j. envexpbot.2019.02.016.

Ye, J., Chen, Q. W., Tao, T. T., Wang, G., \& Xu, F. (2016). Promotive effects of 5-aminolevulinic acid on growth, photosynthetic gas exchange, chlorophyll, and antioxidative enzymes under salinity stress in Prunnus persica (L.) Batseh seedling. Emirates Journal of Food and Agriculture, 28(11), 786-795. http://dx.doi.org/10.9755/ ejfa.2016-06-647.

Zhang, P., Wang, R., Yang, X., Ju, Q., Li, W., Lü, S., Tran, L. P., \& Xu, J. (2020). The R2R3-MYB transcription factor AtMYB49 modulates salt tolerance in Arabidopsis by modulating the cuticle formation and antioxidant defence. Plant, Cell \& Environment, 43(8), 1925-1943. http://dx.doi.org/10.1111/pce.13784. PMid:32406163.

Zhang, S., Yan, Y., Wang, B., Liang, Z., Liu, Y., Liu, F., \& Qi, Z. (2014). Selective responses of enzymes in the two parallel pathways of rosmarinic acid biosynthetic pathway to elicitors in Salvia miltiorrhiza hairy root cultures. Journal of Bioscience and Bioengineering, 117(5), 645651. http://dx.doi.org/10.1016/j.jbiosc.2013.10.013. PMid:24220646.

Zhang, W. F., Zhang, F., Raziuddin, R., Gong, H. J., Yang, Z. M., Lu, L., Ye, Q. F., \& Zhou, W. J. (2008). Effects of 5-aminolevulinic acid on oilseed rape seedling growth under herbicide toxicity stress. Journal of Plant Growth Regulation, 27(2), 159-169. http://dx.doi. org/10.1007/s00344-008-9042-y.

Zhen, A., Bie, Z. L., Huang, Y., Liu, Z. X., \& Fan, M. L. (2012). Effects of 5-aminolevulinic acid on the $\mathrm{H}_{2} \mathrm{O}_{2}$ content and antioxidative enzyme gene expression in $\mathrm{NaCl}$-treated cucumber seedlings. Biologia Plantarum, 56(3), 566-570. http://dx.doi.org/10.1007/ s10535-012-0118-y.

Zhou, W. J., \& Leul, M. (1999). Uniconazole-induced tolerance of rape plants to heat stress in relation to changes in hormonal levels, enzyme activities and lipid peroxidation. Plant Growth Regulation, 27(2), 99-104. http://dx.doi.org/10.1023/A:1006165603300. 